\title{
A água do mar tem tudo
}

\section{Ó mar salgado, \\ Quanto do teu sal são lágrimas \\ de Portugal}

in Mar Portuguez /Mensagem

Fernando Pessoa (1888-1935)

A água do mar, que cobre mais de $70 \%$ da superfície terrestre, é, na sua quase totalidade, $97 \%$, salgada. Nela se têm dissolvido ao longo de milhares de miIhões de anos, várias substâncias, $X$ (sólidas, s, líquidas, I, ou gasosas, g) resultado da interacção com a água, $\mathrm{H}_{2} \mathrm{O}$, com que contactam, que as dispersa no meio aquoso, ex:

$$
X(s) \stackrel{\mathrm{H}_{2} \mathrm{O}}{\longrightarrow} X(a q)
$$

Em cada quilograma de água do mar estão dissolvidos, em média, cerca de $35 \mathrm{~g}$ de sais, que Ihe conferem a salinidade, $\mathrm{S}$, e dos quais o maioritário é o cloreto de sódio, $\mathrm{NaCl}$. A água do mar submetida a evaporação deixa como depósito o sal (das cozinhas), mistura de cloreto de sódio com outros sais em quantidades menores.

A composição da solução é consequência da maior ou menor abundância em que essas várias substâncias existem e das respectivas solubilidades na água. A tabela que se apresenta com a composição média aproximada da água do mar é um exemplo simplificado. Muitos outros elementos nela existirão, em espécies químicas de concentrações vestigiárias, por vezes abaixo dos limites

* CECUL - Departamento de Química e Bioquímica, Faculdade de Ciências da Universidade de Lisboa (fcamoes@fc.ul.pt) de detecção dos métodos de análise. A solubilização de substâncias moleculares na água traduz-se na dispersão das moléculas de soluto pelo solvente. $\mathrm{Na}$ solubilização das substâncias minerais em água, as moléculas dispersam-se e dissociam-se ou ionizam-se nos seus iões, ex:

$\mathrm{NaCl}(\mathrm{s}) \stackrel{\mathrm{H}_{2} \mathrm{O}}{\longrightarrow} \mathrm{NaCl}(a q) \rightarrow \mathrm{Na}^{+}+\mathrm{Cl}^{-}$

conferindo à água do mar a força iónica, I,que é semelhante à do soro fisiológico.

$$
I=\frac{1}{2} \sum_{i} c_{i} z_{i}^{2}=0,71 M
$$

As primeiras observações da composição química da água do mar cedo revelaram que, por entradas de água doce e por acção de temperaturas mais ou menos elevadas, há águas mais ou menos salgadas, mas a proporção em que os vários solutos estão presentes mantém-se.

Os métodos recomendados para a determinação da salinidade da água do mar, são fundamentalmente dois, um método químico e um método físico.

No método químico, método de Knudsen, faz-se a determinação da clorinidade, que se baseia no doseamento volumétrico dos aniões $\left(\mathrm{Cl}^{-}, \mathrm{Br}, \mathrm{I}^{-}\right)$que, por adição do titulante, solução padrão de nitrato de prata, $\mathrm{AgNO}_{3}$, formam com o ião prata, $\mathrm{Ag}^{+}$, um precipitado branco de compostos pouco solúveis (ditos insolúveis), $\mathrm{AgCl}, \mathrm{AgBr}, \mathrm{Agl}$.

$$
\begin{aligned}
\mathrm{Ag}^{+}(a q)+\mathrm{Cl}^{-}(a q) & \rightleftarrows \mathrm{AgCl}(s) \\
\mathrm{Ag}^{+}(a q)+\mathrm{Br}^{-}(a q) & \rightleftarrows A g B r(s) \\
\mathrm{Ag}^{+}(a q)+I^{-}(a q) & \rightleftarrows A g I(s)
\end{aligned}
$$

Dado que o cloreto é largamente maioritário, considera-se que a massa de precipitado é praticamente toda ela cloreto de prata, definindo-se clorinidade, $\mathrm{Cl}$ (\%), como a massa, g, de "cloro", (Cl), correspondente a cada quilograma, kg, (aproximadamente $1 \mathrm{~L}$ ) de água do mar. O ponto de equivalência da titulação é indicado pelo início da formação de um segundo precipitado corado entre $\mathrm{Ag}^{+} \mathrm{e}$ $\mathrm{CrO}_{4}{ }^{2-}$, do cromato de potássio adicionado como indicador.

Data de 1902 a primeira equação empírica usada para converter valores de $\mathrm{Cl}$ (\%o), em valores de salinidade absoluta, S\%:

$S(\%)=0,03+1,805 \mathrm{Cl}(\% \circ)$

Em 1969, a UNESCO propôs uma nova relação

\section{$\mathrm{S}(\% \circ)=1,80655 \mathrm{Cl}(\% \circ)$}

A uma salinidade de 35\% corresponde uma clorinidade de 19,374\%.

O método físico, ou método prático, consiste na comparação da condutividade eléctrica da água a analisar, com a condutividade de uma água do mar padrão de condutividade conhecida, medidas em salinómetros, que são condutímetros especialmente desenhados para o efeito. Definida desta forma, a salinidade é uma grandeza sem dimensões. A condutividade de uma água do mar de salinidade 35 é de cerca de $60 \mathrm{mS}$ $\mathrm{cm}^{-1}$, dependendo da temperatura (a condutividade de uma água de elevado grau de pureza, contendo praticamente 
apenas os iões $\mathrm{H}^{+}$e $\mathrm{OH}^{-}$resultantes da sua auto-ionização é da ordem de $4 \mathrm{x}$ $10^{-2} \mu \mathrm{S} \mathrm{cm}^{-1}$ ).

A reacção química apresentada, característica do ião cloreto com o ião prata, é uma das reacções químicas de maior utilidade analítica, servindo de base ao método de referência em situações de utilidade prática tão diversificadas como análises ambientais, de produtos alimentares e análises clínicas. Passamos a apresentá-la como suporte para esclarecer conceitos como solubilidade, produto de solubilidade, equilíbrio de solubilidade, solução saturada e solução sobressaturada.

A constante de equilíbrio, $K_{s p}(\mathrm{AgCl})$, fornece a indicação termodinâmica das condições em que, por adição de $\mathrm{AgNO}_{3}$ a uma solução contendo iões cloreto, $\mathrm{Cl}^{-}$ , a precipitação se inicia, bem como da extensão em que ela ocorre: quando a concentração de $\mathrm{Ag}^{+}$em solução é tal que se atinge a condição

$K_{s p}(\mathrm{AgCl})=\left[\mathrm{Ag}^{+}\right]\left[\mathrm{Cl}^{-}\right]=1,8 \times 10^{-10}$ (a $25^{\circ} \mathrm{C}$ ).

Nessa altura a solução está saturada em $\mathrm{AgCl}$ dissociado nos seus iões $\mathrm{Ag}^{+}$e $\mathrm{Cl}^{-}$.

Caso a solução não contenha outras fontes de $\mathrm{Ag}^{+}$ou $\mathrm{Cl}^{-}$, eles estão em concentrações iguais,

$\left[\mathrm{Ag}^{+}\right]=\left[\mathrm{Cl}^{-}\right]=S_{\mathrm{AgCl}}=K_{s p}(\mathrm{AgCl})^{1 / 2}=1,3$ $\times 10^{-5} \mathrm{M}$,

o que corresponde à concentração analítica de cloreto de prata na solução saturada, $[\mathrm{AgCl}]=1,3 \times 10^{-5} \mathrm{M}$.

A partir daí, a adição de mais solução de $\mathrm{AgNO}_{3}$, provoca abaixamento da solubilidade de $\mathrm{AgCl}$, com remoção progressiva mais $\mathrm{Cl}^{-}$da solução para o precipitado (princípio de le Chatelier), o que continuará a garantir o equilíbrio heterogéneo entre o sal sólido e os seus iões em solução. A concentração de $\mathrm{Cl}^{-}$em solução vai diminuindo e a de $\mathrm{Ag}^{+}$vai aumentando, mantendo-se o produto de solubilidade.

Quando a concentração de $\mathrm{Ag}^{+}$atinge um valor tal que, para a concentração de $\mathrm{CrO}_{4}{ }^{2-}$ existente em solução (adicionado como indicador), se iguala o produto de solubilidade do cromato de prata, $\mathrm{Ag}_{2} \mathrm{CrO}_{4}$ (menos solúvel que
AgCl), estão reunidas as condições termodinâmicas para que se inicie esta segunda precipitação.

\section{$2 \mathrm{Ag}^{+}(a q)+\mathrm{CrO}_{4}^{2-}(a q) \rightleftarrows \mathrm{Ag}_{2} \mathrm{CrO}_{4}(s)$}

$K_{s p}\left(\mathrm{Ag}_{2} \mathrm{CrO}_{4}\right)=\left[\mathrm{Ag}^{+}\right]^{2}\left[\mathrm{CrO}_{4}{ }^{2-}\right]=2,4 \mathrm{x}$ $10^{-12}$ (a $25^{\circ} \mathrm{C}$ )

Dado que os iões $\mathrm{Ag}^{+}$são comuns aos dois equilíbrios de solubilidade, do $\mathrm{AgCl}$ e do $\mathrm{Ag}_{2} \mathrm{CrO}_{4}$, a solubilidade $S_{\mathrm{AgCl}}$ é medida pela concentração dos iões $\mathrm{Cl}^{-}$ que vêm exclusivamente do $\mathrm{AgCl}$ :

\section{$S_{\mathrm{AgCl}}=\left[\mathrm{Cl}^{-}\right]=K s(\mathrm{AgCl}) /\left[\mathrm{Ag}^{+}\right]$.}

A solubilidade do cromato de prata é, por sua vez dada pela concentração dos iões $\mathrm{CrO}_{4}{ }^{2-}$, cada um proveniente da dissociação de $\mathrm{Ag}_{2} \mathrm{CrO}_{4}, \mathrm{~S}_{\mathrm{Ag} 2 \mathrm{CrO} 4}=$ $\left[\mathrm{CrO}_{4}{ }^{2-}\right]=K_{s p}\left(\mathrm{Ag}_{2} \mathrm{CrO}_{4}\right) /\left[\mathrm{Ag}^{+}\right]^{2} . \mathrm{Em}$ situações em que iões cromato e iões prata venham exclusivamente de dissociação de cromato de prata, isto é, na ausência de iões comuns, cada $\mathrm{Ag}_{2} \mathrm{CrO}_{4}$, dissocia-se num ião cromato, $\mathrm{CrO}_{4}{ }^{2-}$, e em dois iões prata, $\mathrm{Ag}^{+}$, e é $K_{s p}\left(\mathrm{Ag}_{2} \mathrm{CrO}_{4}\right)=(2 \mathrm{~S})^{2} \mathrm{~S}$, sendo a solubilidade de cromato de prata, $\mathrm{S}_{\mathrm{Ag} 2 \mathrm{CrO} 4}=$ $\left(K_{s p}\left(\mathrm{Ag}_{2} \mathrm{CrO}_{4}\right) / 4\right)^{1 / 3}=\left(6 \times 10^{-13}\right)^{1 / 3}=$ $8,4 \times 10^{-5} \mathrm{M}$.

A presença de um precipitado é o garante de que se verifica equilíbrio de solubilidade entre o precipitado e a solução saturada de soluto na solução; nessas circunstâncias a concentração de soluto representa o valor da sua solubilidade. Não havendo observação visual da presença de precipitado, não se pode afirmar de antemão que a solução está saturada, ou com concentração inferior ou superior (sobressaturada) ao valor da solubilidade.

Solubilidade - composição analítica de uma solução saturada, expressa em termos da proporção de um dado soluto num determinado solvente. Pode exprimir-se como concentração, molalidade, fracção molar, ou outra relação mássica.

Para que ocorra a formação de um precipitado não basta que se observe a condição termodinâmica, isto é, produto iónico igual ao produto de solubilidade, $K_{i}=K_{s p}$. Tal como em qualquer transformação há aspectos de natureza cinética que afectam as condições de precipitação. Para que se inicie uma precipitação, a solução tem que estar sobressaturada. Os iões e as moléculas em solução adquirem estabilidade quer pelas camadas iónicas em seu redor quer pelas esferas de hidratação, que impedem que se agreguem em núcleos de partículas de dimensão suficientemente grande que permita a sua precipitação. Os mecanismos de precipitação são bastante específicos de cada substância, variando o grau de sobressaturação requerida por cada uma. O cloreto de prata e o sulfato de prata são exemplos opostos muito estudados, representando o $\mathrm{BaSO}_{4}$ um exemplo típico de um composto que só inicia a sua precipitação quando se atingem elevados níveis de sobressaturação, isto é, produto iónico, $K_{i}>>K_{s p}$, neste caso com níveis de concentração de $\mathrm{BaSO}_{4}$ em solução cerca de 160 vezes superiores à sua solubilidade em água (160 $S=1,63 \times 10^{-3}$ M). Tal corresponde a situações meta-estáveis e uma vez iniciada a precipitação, passado algum tempo, ela ocorre muito rapidamente, atingindo-se equilíbrio termodinâmico entre precipitado e iões $\mathrm{Ba}^{2+} \mathrm{e} \mathrm{SO}_{4}^{2-}$ em solução.

$\mathrm{Ba}^{2+}(\mathrm{aq})+\mathrm{SO}_{4}^{2-}(\mathrm{aq}) \rightarrow \mathrm{BaSO}_{4}(\mathrm{~s})$

$K_{s p}\left(\mathrm{BaSO}_{4}\right)=\left[\mathrm{Ba}^{2+}\right]\left[\mathrm{SO}_{4}{ }^{2-}\right]=1,04 \times 10^{-10}$ (a $25^{\circ} \mathrm{C}$ )

$S=\left(K_{s p}\right)^{1 / 2}=1,02 \times 10^{-5} \mathrm{M}$

Esta reacção de formação de um precipitado entre ião sulfato e ião bário está na base do método gravimétrico de referência (e do método turbidimétrico) para a quantificação do ião sulfato também existente na água do mar e em águas de abastecimento público onde, por imposição legal, tem que ser avaliado, dadas as suas implicações com fenómenos anaeróbios indesejáveis.

Tabela: Componentes maioritários da água do mar, $\mathrm{S}=35 \%$.

\begin{tabular}{cc}
\hline Componente & $\begin{array}{c}\text { Composição } \\
\text { (mol kg-1) }\end{array}$ \\
\hline $\mathrm{NaCl}$ & 0,4186 \\
$\mathrm{MgCl}_{2}$ & 0,0596 \\
$\mathrm{Na}_{2} \mathrm{SO}_{4}$ & 0,02856 \\
$\mathrm{KCl}$ & 0,01 \\
$\mathrm{CaCl}_{2}$ & 0,005 \\
\hline
\end{tabular}

